\title{
Ethyl pyruvate protects against sepsis- associated encephalopathy through inhibiting the NLRP3 inflammasome
}

Xiaoli Zhong ${ }^{1,2}$, Lingli Xie ${ }^{1,2}$, Xiaolong Yang ${ }^{1,2}$, Fang Liang ${ }^{1}$, Yanliang Yang ${ }^{2,3}$, Jianbin Tong ${ }^{4}$, Yanjun Zhong ${ }^{1,2,5}$, Kai Zhao ${ }^{1}$, Yiting Tang ${ }^{2,3^{*}}$ (i) and Chuang Yuan ${ }^{1,2^{*}}$

\begin{abstract}
Background: With the advance of antibiotics and life support therapy, the mortality of sepsis has been decreasing in recent years. However, the incidence of sepsis-associated encephalopathy (SAE), a common complication of sepsis, is still high. There are few effective therapies to treat clinical SAE. We previously found that ethyl pyruvate (EP), a metabolite derivative, is able to effectively inhibit the NLRP3 inflammasome activation. Administration of ethyl pyruvate protects mice against polymicrobial sepsis in cecal ligation and puncture (CLP) model. The aim of present study is to investigate if ethyl pyruvate is able to attenuate SAE.
\end{abstract}

Methods: After CLP, C57BL/6 mice were intraperitoneally or intrathecally injected with saline or ethyl pyruvate using the sham-operated mice as control. New Object Recognition (NOR) and Morris Water Maze (MWM) were conducted to determine the cognitive function. Brain pathology was assessed via immunohistochemistry. To investigate the mechanisms by which ethyl pyruvate prevent SAE, the activation of NLRP3 in the hippocampus and the microglia were determined using western blotting, and cognitive function, microglia activation, and neurogenesis were assessed using WT, NIrp3 $3^{-/-}$and $\mathrm{Asc}^{-/-}$mice in the sublethal CLP model. In addition, N/rp3 $3^{-/-}$ and $\mathrm{AsC}^{-1-}$ mice treated with saline or ethyl pyruvate were subjected to CLP.

Results: Ethyl pyruvate treatment significantly attenuated CLP-induced cognitive decline, microglia activation, and impaired neurogenesis. In addition, EP significantly decreased the NLRP3 level in the hippocampus of the CLP mice, and inhibited the cleavage of IL-1 $\beta$ induced by NLRP3 inflammsome in microglia. NLRP3 and ASC deficiency demonstrated similar protective effects against SAE. N/rp3 $3^{-/-}$and $\mathrm{AsC}^{-/-}$mice significantly improved cognitive function and brain pathology when compared with WT mice in the CLP models. Moreover, ethyl pyruvate did not have additional effects against SAE in $\mathrm{Nrrp}^{-/-}$and $\mathrm{Asc}^{-/-}$mice.

Conclusion: The results demonstrated that ethyl pyruvate confers protection against SAE through inhibiting the NLRP3 inflammasome.

Keywords: Sepsis-associated encephalopathy, Ethyl pyruvate, NLRP3 inflammasome, Innate immunity, Sepsis

\footnotetext{
* Correspondence: yitingtang@csu.edu.cn; aeolus.yc@csu.edu.cn

2Department of Pathophysiology, School of Basic Medical Science, Central

South University, 138 Tong-zi-po Road, Changsha, Hunan Province 410000, P.

R. China

'Department of Hematology and Critical Care Medicine, The 3rd Xiangya

Hospital, Central South University, Changsha, Hunan Province 410000, P. R.

China

Full list of author information is available at the end of the article
}

(c) The Author(s). 2020 Open Access This article is licensed under a Creative Commons Attribution 4.0 International License, which permits use, sharing, adaptation, distribution and reproduction in any medium or format, as long as you give

appropriate credit to the original author(s) and the source, provide a link to the Creative Commons licence, and indicate if changes were made. The images or other third party material in this article are included in the article's Creative Commons licence, unless indicated otherwise in a credit line to the material. If material is not included in the article's Creative Commons licence and your intended use is not permitted by statutory regulation or exceeds the permitted use, you will need to obtain permission directly from the copyright holder. To view a copy of this licence, visit http://creativecommons.org/licenses/by/4.0/ 


\section{Introduction}

Sepsis is a systemic inflammatory response syndrome (SIRS) caused by infection (Buras et al. 2005; Singer et al. 2016). Due to the advance of medicines and lifesupport techniques, the mortality of sepsis have been decreasing in recent years (Martin et al. 2003; Tanriover et al. 2006; Gaieski et al. 2013; Kaukonen et al. 2014; Stevenson et al. 2014; O'Neill 2016; Kaufmann et al. 2018). In addition to high mortality at the early stage, sepsis can cause sepsis-associated encephalopathy (SAE), which significantly increases the mortality of patients and largely influences the life quality of sepsis survivors (Eidelman et al. 1996; Ebersoldt et al. 2007; Widmann et al. 2014; Annane and Sharshar 2015). SAE is characterized by diffuse brain dysfunction after the onset of sepsis, without infection in the central nervous system (Eidelman et al. 1996; Ebersoldt et al. 2007; Chen et al. 2014; Widmann et al. 2014; Annane and Sharshar 2015). It has been reported that approximately $70 \%$ of survivors recovered from severe systemic infection have cognitive deficits (Iwashyna et al. 2010; Gofton and Young 2012). However, the underlying mechanisms of SAE are not fully uncovered and effective medicines for treating SAE are not available in clinics.

Previous studies have suggested that inflammatory responses, especially the inflammasome activation, is critical for the development of SAE (Yende et al. 2008; Erickson and Banks 2011; Annane and Sharshar 2015). Among different types of the inflammasomes, the NLRP3 (NLR family pyrin domain containing 3) inflammasome is the most well-characterized inflammasome (Hise et al. 2009) and contributes to the development of a number of monogenic autoinflammatory diseases, including the inherited CAPSs Muckle-Wells syndrome (MWS), familial cold autoinflammatory syndrome and neonatal-onset multisystem inflammatory disease (Masters et al. 2009), as well as various metabolic and neurodegenerative disorders(Wen et al. 2012), (De et al. 2014). However, whether pharmacological inhibition of the NLRP3 inflammasome could attenuate SAE is not known.

Pyruvate (CH3COCOO-), a key intermediate molecule in glucose metabolism, plays a protective role in many organ system damage models in vitro and in vivo (Bunton 1949; O'Donnell-Tormey et al. 1987; Salahudeen et al. 1991; Deboer et al. 1993; Nath et al. 1995; Cicalese et al. 1996; Crestanello et al. 1998; Dobsak et al. 1999). However, the poor stability in solution limits its therapeutic application in clinics (Montgomery and Webb 1956; Korff 1964). In 2001, Sims et al. discovered a stable derivative of metabolic intermediates pyruvate, named ethyl pyruvate (EP) (Sims et al. 2001), which is commonly used as a nontoxic food additive. Studies show that Ethyl pyruvate (EP) exerts protective effects in burn injury, shock, necrotizing pancreatitis and radiation-induced complications (Fink
2007) in a manner similar to pyruvate (Ulloa et al. 2002). In addition, EP treatment exerts an anti-inflammatory effect in various diseases such as sepsis (Miyaji et al. 2003; Sappington et al. 2003), alcoholic liver injury (Yang et al. 2003) and acute kidney injury (Salahudeen et al. 1991). We recently found that EP is a novel NLRP3 inhibitor (Li et al. 2018). However, whether EP treatment could improve cognitive function in SAE is still unknown. The aim of present study is to investigate the effect of EP in the SAE.

\section{Methods}

\section{Animals}

C57BL/6 (WT), $\mathrm{Nlrp3}^{-/-}$and $\mathrm{Asc}^{-/-}$male mice with age of 8-10 weeks and body weight of $20-25 \mathrm{~g}$ were used in the present study. C57BL/6 ( $\mathrm{H}-2 \mathrm{~Kb}$, Thy-1.2) mice were purchased from Hunan SJA Laboratory Animal Co.Ltd. (Changsha, China). The $\mathrm{Nlrp3}^{-/-}$mice and $\mathrm{Asc}^{-/-}$mice (Mariathasan et al. 2004) were donated by Rongbin Zhou (CAS Key Laboratory of Innate Immunity and Chronic Disease, School of Life Sciences, University of Science and Technology of China). Mice were housed in the animal facility of Central South University and were maintained under standard condition (room temperature $22-25^{\circ} \mathrm{C}$ with a 12 -h light-dark cycle). Mice had free access to standard chow and water and had been acclimatized for at least 1 week before conducting experiments. Animal care and experimental procedures were performed with the approval from the Institutional Animal Care and Use Committees of Central South University.

\section{Sepsis model}

\section{Cecal ligation and puncture}

After the mice anesthetized by $10 \mathrm{mg} / \mathrm{kg}$ xylazine hydrochloride and $200 \mathrm{mg} / \mathrm{kg}$ ketamine hydrochloride, a $1.5 \mathrm{~cm}$ longitudinal midline incision was made at the shaved and disinfected skin of lower quadrants of the abdomen and the cecum was exteriorized. The cecum was ligated at half between distal pole and the base of the cecum with 4-0 silk suture and a through-and-through puncture was made from mesenteric toward antimesenteric direction after medium ligation using 21-gauge needles. A small amount (droplet) of feces was extruded from both the mesenteric and antimesenteric penetration holes to ensure patency. The abdomen was closed and the mice were injected with pre-warmed normal saline $\left(37^{\circ} \mathrm{C} ; 5 \mathrm{ml}\right.$ per $100 \mathrm{~g}$ body weight) subcutaneously to allow mice to recover from anaesthetization. Sham-operated animals were submitted to laparotomy and the cecum was taken out without puncture after laparotomy for sham operation.

\section{Intrathecal injections}

Intrathecal injection was performed according to the protocol of Hayden and Wilcox (Hylden and Wilcox 
1983). Anesthetized mice were slowly injected with $5 \mu \mathrm{L}$ of PBS or EP between the L5 and L6 regions of the spinal cord using a 30-gauge needle $30 \mathrm{~min}$ after CLP operation.

\section{Behavioral tests \\ Open field test}

As described previously, open field tests were carried out to evaluate the locomotor activity of mice (Zhang et al. 2013). To put it simply, the mice were gently placed in the center of the open field $(50 \times 50 \mathrm{~cm})$. The movement of the mouse was recorded by computerized video tracking system (Logitech, Suzhou, China). The total traveled distance and average speed are analyzed by smart junior software 3.0 (Panlab, Cambridge, USA).

\section{Novel object recognition}

Novel object recognition experiment was carried out in a field arena of $20 \mathrm{~cm} \times 30 \mathrm{~cm} \times 30 \mathrm{~cm}$. The test consists of two stages, namely, the training phase and the test phase (Bevins and Besheer 2006; Leger et al. 2013; Volmar et al. 2017; Briz et al. 2017). During the training phase, two identical objects are placed in symmetrical positions at equal distances from the center of the arena and from the walls of the arena. The mice were gently placed in the center of arena, with their heads opposite to the two identical objects, allowing them to explore freely for $10 \mathrm{~min}$. Twenty-four hours post the training, one of the familiar items was replaced with a novel item, and the mouse was allowed to explore for $10 \mathrm{~min}$ in the arena. The objects and the chamber were cleaned with $75 \%$ alcohol solution between trials during training and testing. The preference index is defined as previous study (Qing et al. 2018).

\section{Morris water maze test}

The Morris water maze test was performed on the 15th day after the operation to evaluate spatial learning and memory of the mice. We used a computer video tracking system (Logitech, Suzhou, China) to record the movement of mice in water maze, according to previous research methods (He et al. 2012). To put it simply, a transparent circular platform is placed in the southwest quadrant of the circular pool $1 \mathrm{~cm}$ below the water surface. During the training period, the mice were first placed on the platform for $30 \mathrm{~s}$ to conform themselves to the environment, and then the mice were released into the water. In each experiment, mice were allowed to find the platform for a maximum of $60 \mathrm{~s}$. If the mouse fails to find the platform within $60 \mathrm{~s}$, it is guided to the platform and stays on the platform for $30 \mathrm{~s}$. All mice were trained for 4 days, three times a day, changing releasing quadrant each trial, and the latency to platform was recorded in each experiment. After 4 days of training, take the platform out of the swimming pool on the fifth day. The mice were released into the water from the northeast quadrant. The movement trajectory of mice within $60 \mathrm{~s}$ was recorded. The memory ability of mice was evaluated by the number of platform crossings and the percentage of search time in the target quadrant.

\section{Immunostaining}

The brains were obtained from the anesthetized mice. Half of the brain is used for immunostaining and the other half for Western blotting. The hemi-encephalon used for immunostaining was fixed overnight in $4 \%$ paraformaldehyde. After dehydration with sucrose, the brain was embedded in OCT and the coronal section $(20 \mu \mathrm{m})$ of the brain was cut continuously by hypothermia thermostats. The slices were blocked with 5\% BSA and 0.1\% TritonX100 for $1 \mathrm{~h}$ at room temperature, and incubated with rabbit polyclonal antibody (rabbit polyclonal antibody to ionized calcium binding adaptor molecule 1(IBA1):1:500, Wako, Japan, 10,904; rabbit polyclonal antibody to double cortin:1:500, CST, 4604) at $4{ }^{\circ} \mathrm{C}$ overnight. The slices were incubated in secondary antibody (1: 500) for $2 \mathrm{~h}$. Three times of washes using $0.01 \mathrm{M}$ PBS were conducted between each step. All the pictures were taken by microscope (Eclipse80i, Nikon, Japan) at the same light intensity and exposure time, and the executors were blind to the experimental conditions.

For immunofluorescence staining of ASC speck, mouse microglia loaded on 6-well slides were primed with ultrapure LPS $(100 \mathrm{ng} / \mathrm{ml}$ for $3 \mathrm{~h}$. in the presence or the absence of EP $(10 \mathrm{mM})$, and then stimulated with nigericin $(10 \mu \mathrm{M})$ for $30 \mathrm{~min}$. The microglia was fixed for $15 \mathrm{mins}$ in $4 \%$ paraformaldehyde, and blocked with 5\% BSA and 0.1\% TritonX-100 for $1 \mathrm{~h}$ at room temperature, followed by an incubation with rabbit polyclonal antibody (rabbit polyclonal anti-ASC antibody Adipogen AL177: 1:200, InvivoGen, A120-100D2) at $4{ }^{\circ} \mathrm{C}$ overnight. Afterward, the microglia were incubated in secondary antibody (1:500) for $2 \mathrm{~h}$. Three times of washes using 0.01 M PBS were conducted between each step. All the pictures were taken by microscope (Eclipse80i, Nikon, Japan) at the same light intensity and exposure time, and the executors were blind to the experimental conditions.

\section{Western blot}

To detect the NLRP3 and the DCX level of hippocampus (neonatal neurons), the frozen hippocampus was homogenized for proteins in a lytic buffer containing protease inhibitor cocktails (Roche, Germany, catalog number: 11873580001), followed by a centrifugation at $12,000 \mathrm{~g}$ for $20 \mathrm{~min}$ at $4{ }^{\circ} \mathrm{C}$. The supernatant of the hippocampal homogenate was then collected. To determine the expression of NLRP3 and cleavage of pro-IL-1 $\beta$ in 
microglia, supernatant and cell lysates of microglia were analyzed using western blot. Cell-free supernatants were used to extracted proteins by methanol/chloroform precipitation as previously described (Wang et al. 2004; Li et al. 2018). Briefly, cell culture supernatants were precipitated by the addition of an equal volume of methanol and $25 \%$ volumes of chloroform, then were vortexed and centrifuged for $5 \mathrm{~min}$ at $20,000 \mathrm{~g}$. The upper phase was discarded and $400 \mu \mathrm{l}$ methanol was added to the interphase. After a centrifuge for $5 \mathrm{~min}$ at 20,000 g, the supernatants were removed. The protein pellet was dried at $55^{\circ} \mathrm{C}$ for $2 \mathrm{~min}$, and resuspended in Laemmli buffer and boiled for $10 \mathrm{~min}$ at $100^{\circ} \mathrm{C}$. Cell extracts were prepared as described previously (Wang et al. 2004). The protein samples were separated by SDS-PAGE and transferred to PVDF membrane (Millipore). After washing, 5\% non-fat milk in TBST buffer was used to block the membrane for $1 \mathrm{~h}$, and then incubated with primary antibodies (rabbit polyclonal antibody to double cortin: 1:1000, Cell Signaling Technology, catalog number: \#4604; mouse anti-NLRP3 antibody:1:1000, AdipoGen, catalog number: AG-20Boo14; goat anti-IL-1B polyclonal antibody:1:1000, RD systems, catalog number: AF-401-NA; Mouse anti- $\beta$-actin polyclonal antibody: 1:5000, Cell Signaling Technology, catalog number: $\# 3700 \mathrm{~s}$ ) overnight on $4^{\circ} \mathrm{C}$. After washes for three times, the membranes were incubated with secondary antibody at room temperature for $2 \mathrm{~h}$. Finally, the protein was visualized by Western Bright ECL-Spray (advansta, catalog number: K-12049-D50), and the intensity of each band was measured by density method.

\section{Statistical analysis}

All statistical analyses were performed using GraphPad Prism Software (version6.0) and $P<0.05$ was considered statistically significant. Analysis of Variance (ANOVA) and post-hoc test were used to compare more than two groups. The mean and Standard Error of Mean were calculated in experiments with multiple data points.

\section{Results \\ Ethyl pyruvate attenuates cognitive decline in experimental sepsis}

To determine whether ethyl pyruvate could improve learning and memory dysfunction in septic mice, we used NOR and MWM test after the mice subjected to moderate CLP or sham operation. After the mouse restored its mobility (Day 12, Fig. 1b), we carried out NOR test (Day 13) which was followed by MWM test (Day 15 ). We found that the mice in the CLP group had a discrimination index around 0.5 in the test phase (Fig. 1d), which indicated that the mice lost the memory of the old object and were unable to identify the novel object. The mice in the EP-treated and sham group had discrimination indices over 0.6 , which significantly higher than that of the CLP group. In addition, the CLP rendered mice reduced capacity to find the underline platform during both training and test stages as compared to the sham group. EP treatment significantly restored the learning and memory after CLP (Fig. 1e-h). Thus, Ethyl pyruvate attenuates cognitive decline in experimental sepsis..

\section{Ethyl pyruvate attenuates microglia activation and} restores formation of neonatal neurons in septic mice Next we investigate the mechanisms by which EP attenuates cognitive dysfunction in sepsis, we first assessed the activation of microglia, which is one of the most important signs of neuro-inflammation. In young adult mice, the activation of microglial cells in the CA1 region was significantly increased after CLP, and the activation of microglial cells was significantly decreased after EP administration (Fig. 2a\&b). It has been reported that decreased neurogenesis in the granular cell layer of the dentate gyrus is a causal factor of cognitive dysfunction in a series of encephalopathy (Abe 2000; Kim and Diamond 2002; Monje et al. 2002; Nixon and Crews 2010; Encinas et al. 2011). To test whether EP treatment exerts a protective role in improving neurogenesis in SAE, we detected the expression of Doublecortin (DCX), the marker of newborn neuron, in the dentate gyrus (DG) region using immunofluorescence. We found that the level of DCX in the DG region after CLP was significantly decreased, and that EP treatment restored the expression of DCX after CLP (Fig. 2c\&d). These results demonstrated that EP might play a protective role in SAE by promoting neurogenesis and inhibiting the microglia activation in sepsis.

\section{Ethyl pyruvate inhibits NLRP3 inflammasome activation in mouse hippocampus and microglia}

To investigate the effect of EP to NLRP3 inflammsome in the SAE, the levels of NLRP3 of hippocampus in the mice challenged with or without CLP were determined via WB. The results suggested that the CLP model boosted the level of NLRP3 in the hippocampus, and EP significantly restored the increase of NLRP3 (Fig. 3a). In addition, our previous study suggests that EP inhibits the NLRP3 inflammasome activation in mouse macrophages ( $\mathrm{Li}$ et al. 2018). To determine whether ethyl pyruvate (EP) also inhibits the NLRP3 inflammasome activation in mouse microglia, LPS-primed mouse microglia were stimulated with nigericin in the presence or the absence of EP. EP administration notably inhibited cleavage of pro-IL-1 $\beta$ at the concentration of $10 \mathrm{mM}$ (Fig. 3b\&c). Furthermore, EP significantly inhibits ASC speck formation in LPS-primed mouse microglia induced by nigericin (Fig. 3d). These results indicate that 


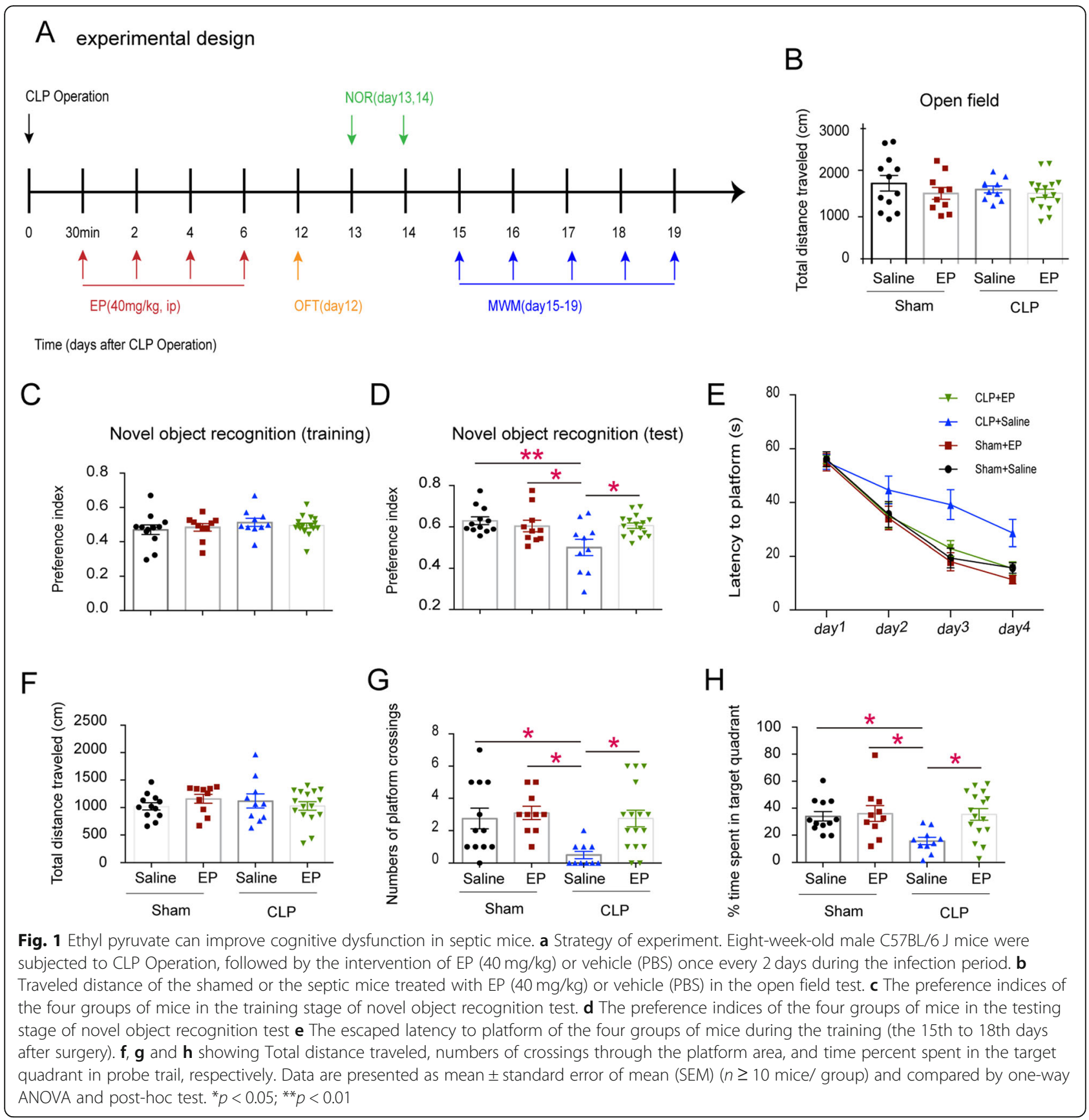

EP inhibits the NLRP3 inflammasome activation in mouse hippocampus and microglia.

\section{Ethyl pyruvate treatment attenuates SAE through inhibition of the activation of NLRP3 inflammasome}

Previous studies showed that ethyl pyruvate inhibited the activation of NLRP3 inflammasomes at the cell level. Thus, we speculate that ethyl pyruvate might inhibit the activation of the NLRP3 inflammasomes in the brain of septic mice. In order to further prove that EP does play a protective role through inhibiting NLRP3 inflammasome, we carried out further experiments on Nlrp3 and Asc knockout mice. We found that NLRP3/ASC deficient mice showed the same degree of cognitive impairment as WT intact mice, and there was no additive protective effect after EP administration (Fig. 4). In addition, we found that Nlrp3 and Asc knockout mice displayed better neurogenesis than WT septic mice (Fig. 5a\&c\&d), and the activation of microglia was significantly decreased (Fig. 5b\&e). These results suggest that EP may inhibit the activation of microglial cells and ameliorate cognitive dysfunction in septic mice by inhibiting the activation of NLRP3 inflammasome. 

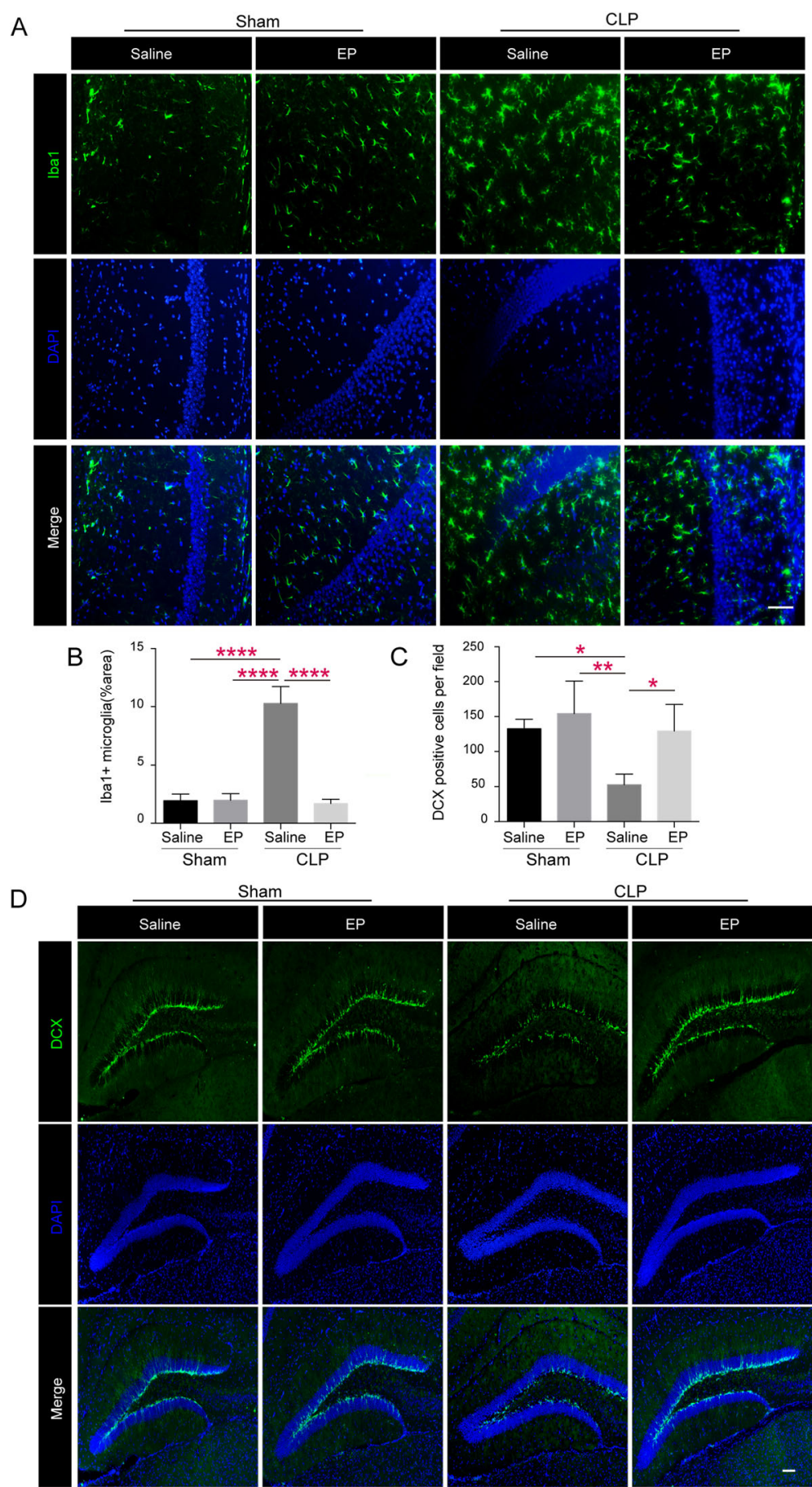

Fig. 2 Ethyl pyruvate attenuates microglia activation and restores formation of neonatal neurons in septic mice. a Microglia activation of shamed or septic mice treated with EP $(40 \mathrm{mg} / \mathrm{kg})$ or vehicle (PBS) was assessed by lba-1 immunofluorescence on postoperative day 12 . Photomicrographs of CA1 areas of the hippocampus are shown infection activated microglia as noted by morphological changes on day 12 , including enlargement of cell bodies, unsmooth synapse, and so on, which was attenuated by EP treatment. Scale bar $=50 \mu \mathrm{m}$. $\mathbf{b} \& \mathbf{c}$ showing area percentage of activated microglia in the CA1 region and DCX positive cells in the dentate genus (DG) of septic mice hippocampus in Sham+Saline, Sham+EP, CLP + Saline and $\mathrm{CLP}+$ EP groups. Data presented as mean \pm SEM ( $n \geq 3$ mice/ group) and compared by one-way ANOVA and post-hoc test, ${ }^{*} P<0.05$, ${ }^{* *} P<0.01$, ${ }^{* * *} P<0.0001$. d Photomicrographs of representative DCX immunofluorescence (Doublecortin, green, neurogenesis) of shamed or septic mice treated with EP (40 mg/kg) or vehicle (PBS) in the DG areas on postoperative day 12. Scale bar $=100 \mu \mathrm{m}$ 


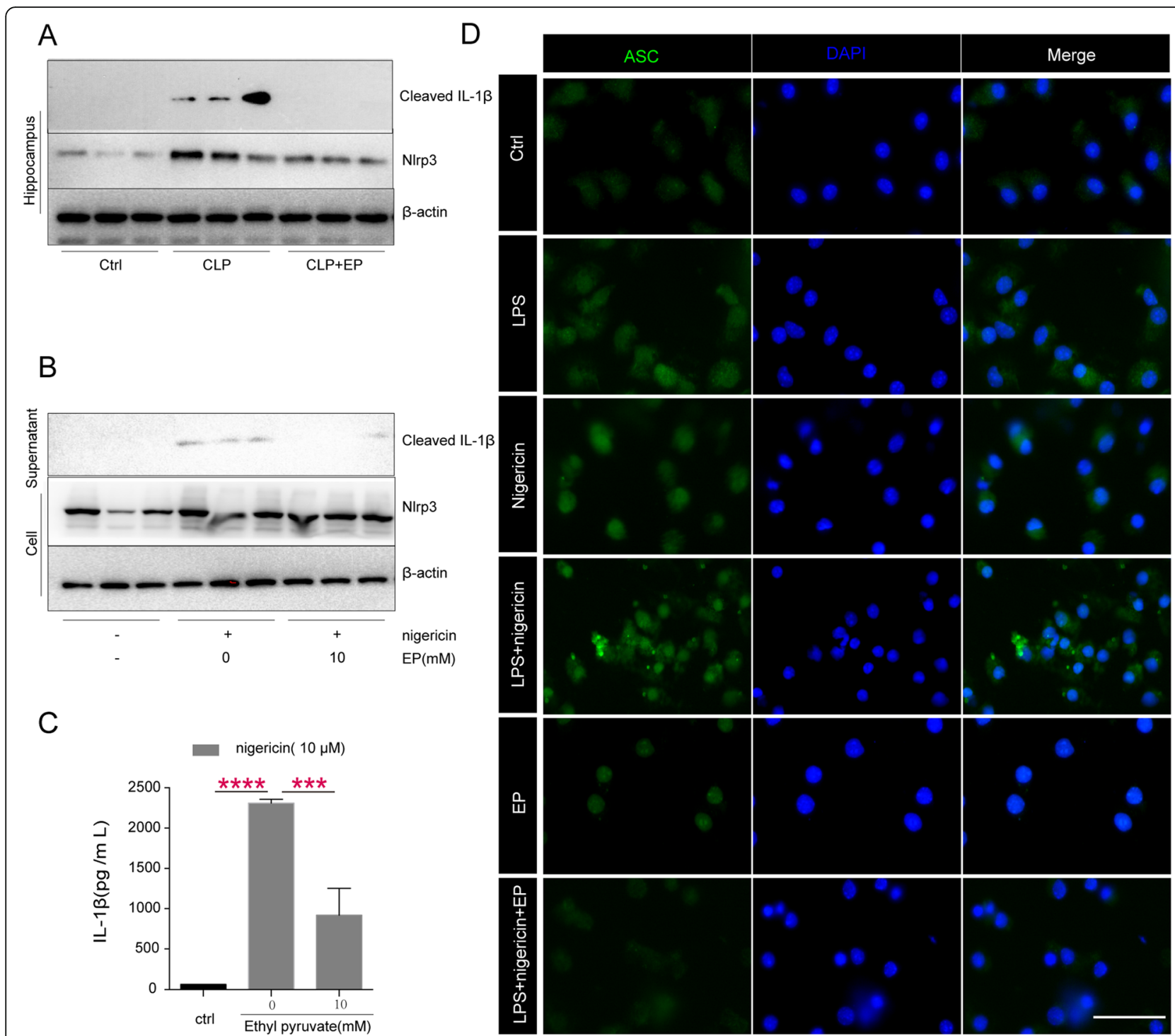

Fig. 3 Ethyl pyruvate inhibits NLRP3 agonists-induced inflammasome activation in mouse microglia. a The expression of NLRP3 in hippocampus were assessed by Western-blot (b) mouse microglia were primed with ultra-pure LPS (100 ng/ml) for $3 \mathrm{~h}$ in the presence or the absence of EP $(10 \mathrm{mM})$, and then stimulated with nigericin $(10 \mu \mathrm{M})$ for $30 \mathrm{~min}$. The release of IL-1 $\beta$ in supernatants and expression of NLRP3 in cell were assessed by Western-blot. $\mathbf{c}$ Levels of IL-1 $\beta$ in the culture medium were determined by ELISA. Data presented as mean \pm SEM ( $n=3$ independent repeats/ group) and compared by one-way ANOVA and post-hoc test, ${ }^{* * *} P<0.001$, ${ }^{* * *} P<0.0001$. $\mathbf{d}$ immunofluorescence of ASC speck in LPSprimed microglia after incubation with nigericin $(10 \mu \mathrm{M})$ for $15 \mathrm{~min}$ in the presence or the absence of ethyl pyruvate (10 mM). Shown in panel $\mathbf{c}$ are representative images of normal and ASC speck. Scale bars, $50 \mu \mathrm{m}$

Intrathecal injection of EP rescued the SAE in the CLP model To test whether EP improves SAE by directly affecting central nervous system or by improving systemic sepsis (secondary effect), we rescued the CLP-challenged mice with the intrathecal injection of EP. NOR tests were conducted to assess the cognitive function in mice after the mice subjected to moderate CLP or sham operation. We found that EP local administration rescued the SAE in the CLP model. The results suggested that local administration of EP significantly restored cognitive impairment in the CLP model (Fig. 6), which indicates that EP, at least in part, has direct effect on brain to improve SAE.

\section{Discussion}

In this study, we found that Ethyl pyruvate treatment significantly attenuated cognitive decline, microglia activation, and impaired neurogenesis in experimental sepsis, at least in part, through inhibition of the NLRP3 inflammasome..

Aberrant activation of the NLRP3 inflammasome in the central nerve system leads to abnormal function of 


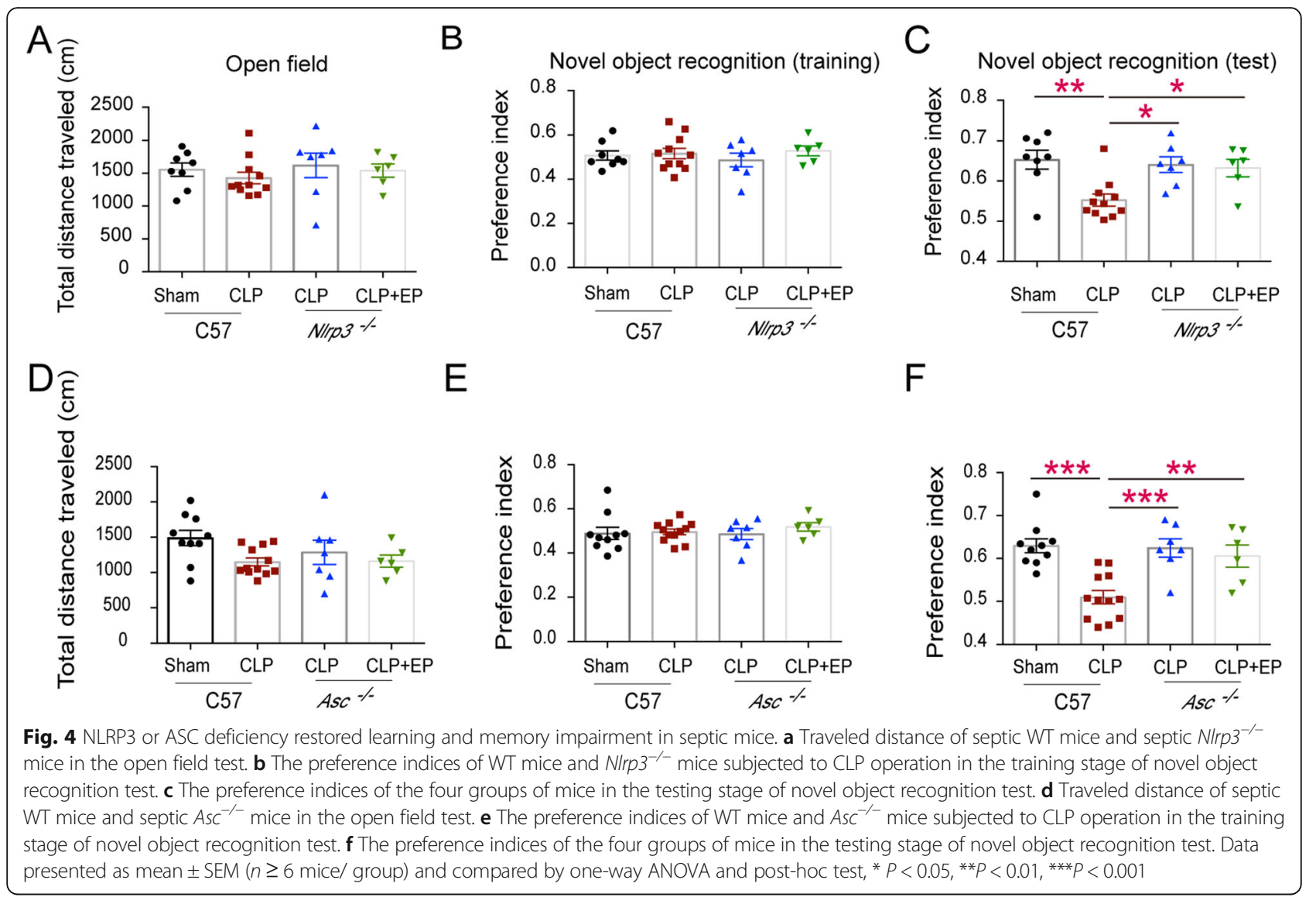

microglia, which contributes to a number of neurodegenerative disorders (Polazzi and Contestabile 2002; Block et al. 2007). The activated microglia can release a range of pro-inflammatory factors, particularly TNF- $\alpha$ and IL- $1 \beta$ (Delgado et al. 1998; Delgado and Ganea 2003; Qin et al. 2004; Burguillos et al. 2011). Previous studies have documented that the activated microglia disrupts neurogenesis, which is implicated in cognitive impairment and mood disorders (Kohman and Rhodes). In the present study, EP significantly restores the cognitive function in sepsis model by inhibiting microglia activation.

The inflammatory cytokines, in particular IL-1 $\beta$, should be the major culprit in the decline of neurogenesis (Kohman and Rhodes). It has been reported that neural progenitor cells (NPCs) express IL-1 receptor and high levels of IL-1 $\beta$ significantly inhibits the proliferation of NPCs and the growth of neurospheres (Green et al. 2012). In addition, the presence of IL- $1 \beta$ facilitates the differentiation of NPCs into astrocyte rather than neurons, which eventually results in the reduction of neurogenesis (Green et al. 2012). These in-vitro studies are phenocopied by invivo studies in which over-expression of IL-1 $\beta$ decreases the number of DCX+ cells (newborn neurons) in the granular layer of the hippocampus (Wu et al. 2012).
Importantly, it is reported that neuroinflammation contributes to the pathogenesis of long-term cognitive impairment of SAE (Wu et al. 2013; Da-ming et al. 2016; Fu et al. 2018). The NLRP3 inflammasome is an intracellular supramolecular complex composed of NLRP3, ASC and caspase-1. Upon activation, ASC is self-assembled into ASC speck (Fernandes-Alnemri et al. 2007), and then activate pro-caspase- 1 by proximal induced autocatalytic activation (Hoss et al. 2016). Finally, activated caspase-1 triggers the maturation of interleukin-1 (IL-1) family cytokines (e.g. IL-1 $\beta$ and IL-18) and facilitates the release of these cytokines via the N-terminal of GSDMD constituted transmembrane pores. Thus, the activation of NLRP3 inflammasome can result in a hyperactive status of immune cells and facilitate the release of IL- $1 \beta$ (Kohman and Rhodes 2013), and may facilitate the disruption of neurogenesis. Previous works reveal that the NLRP3 inflammasome contributes to the pathogenesis of a number of neurodegenerative diseases including Alzheimer's (Heneka et al. 2014; Walsh et al. 2014; Zhang and Jiang 2015), Parkinson's disease (Franchi et al. 2010; Amor et al. 2014; Yan et al. 2015) and Multiple Sclerosis (MS) (Jha et al. 2010; Guo et al. 2015; Weinberg et al. 2015; Yeung et al. 2015; Matthews et al. 2016). In addition, the excessive 


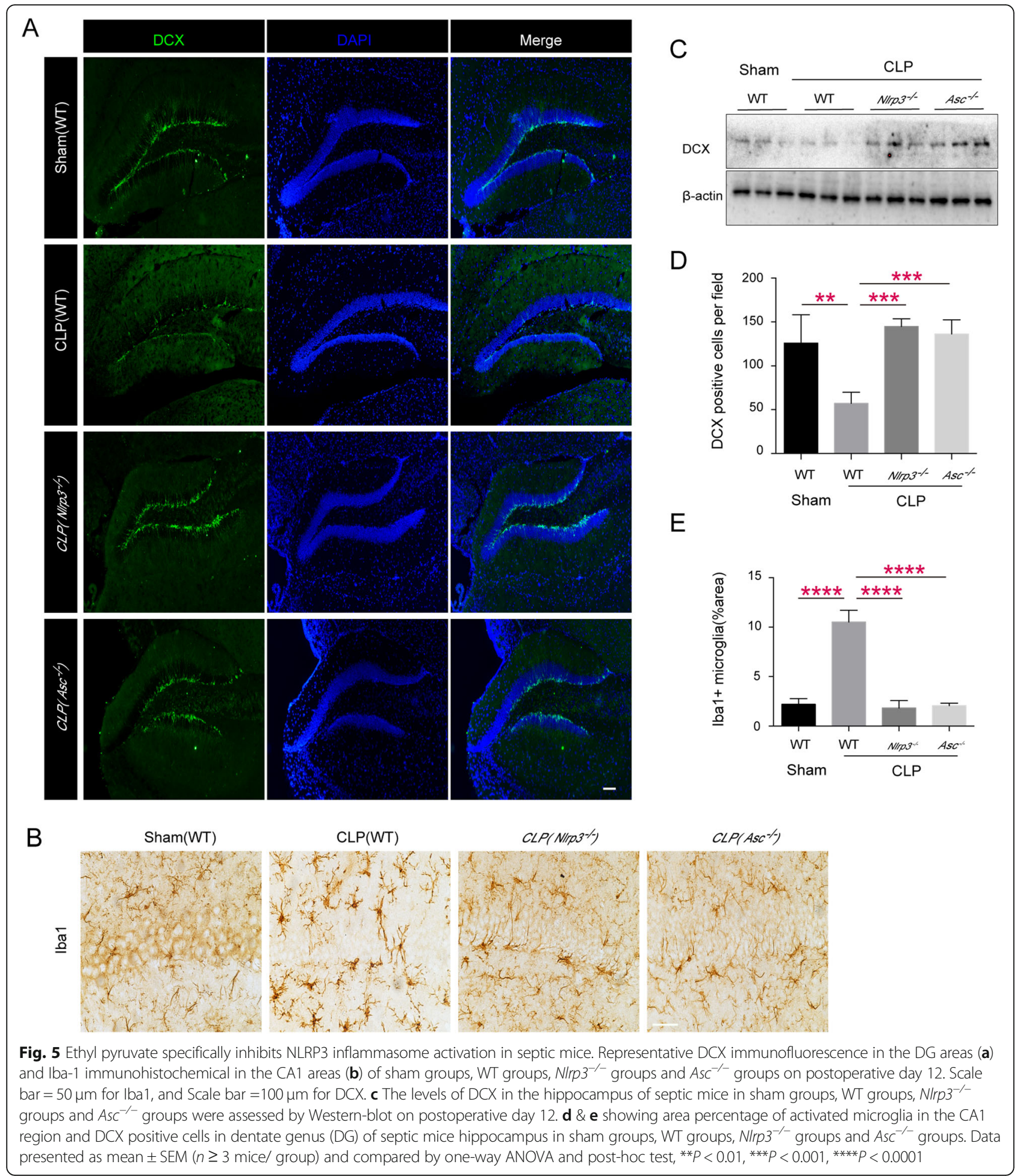

activation of NLRP3 inflammasome promotes memory loss in these diseases (Miller et al. 2009; Kreisel et al. 2014; Zhang et al. 2014; Sui et al. 2016). In line with these observations, we found that ethyl pyruvate treatment significantly inhibited NLRP3 inflammasome activation and IL$1 \beta$ release of microglia, and improved the decline of DCX positive cells and the cognition impairment in the CLP model. Thus, EP attenuates SAE through inhibition of the activation of NLRP3 inflammasome.

Ethyl pyruvate (EP), an anti-inflammatory reagent (O'Donnell-Tormey et al. 1987; Han et al. 2005), is considered as a potential therapeutic drug for various 


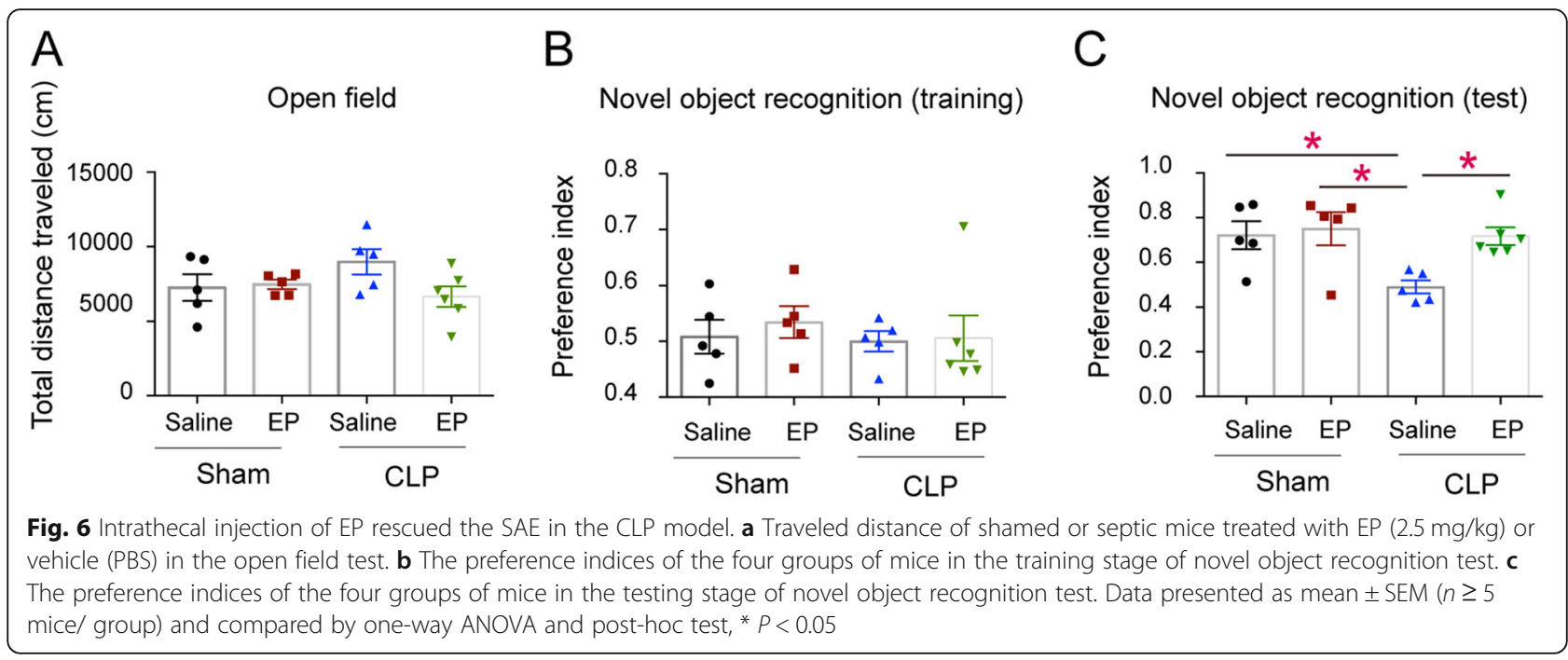

diseases or disorders, including burn injury (Huang et al. 2008), shock (Tawadrous et al. 2002), spinal cord injury (Genovese et al. 2009; Wang et al. 2009), hemorrhagic shock (Slovin et al. 2001), acute endotoxemia (Wang et al. 1999; Ulloa et al. 2002; Venkataraman et al. 2002), severe acute alcoholic hepatitis (Yang et al. 2003) and multiple models of ischemia-reperfusion (Tawadrous et al. 2002; Woo et al. 2004). In sepsis model, EP improves the survival rate of mice when mice administered $24 \mathrm{~h}$ after the onset of sepsis (Ulloa et al. 2002). Other studies suggested that EP can attenuate multiorgan dysfunctions in endotoxemia or sepsis (Miyaji et al. 2003; Hauser et al. 2005). It is important to note that the safety of EP has been confirmed by the long-term application as a food additive (Fink 2003; Organization, F. A., and W. H. Organization 2010). Thus, EP might be a promising medicine in the protection against cognitive dysfunction in sepsis.

\section{Conclusions}

In summary, our results suggest that ethyl pyruvate treatment might improve cognitive function in sepsis through inhibition of the NLRP3 inflammasome.

\section{Abbreviations}

SAE: Sepsis-associated encephalopathy; NLRP3: Pyrin domain-containing 3; IL: Interleukin; CLP: Cecal ligation and puncture; ASC: Apoptosis-associated speck-like protein containing a CARD; EP: Ethyl pyruvate; KO: Knockout; WT: Wild-type; IBA1: Ionized calcium binding adaptor molecule 1; DCX: Doublecortin; DG: Dentate gyrus

\section{Acknowledgments}

We thank the National Natural Science Foundation of China, the Project of Hunan health and the Natural science foundation of Hunan Province for supporting the study.

\section{Authors' contributions}

$Y T T$ and $C Y$ conceived the project. XLZ designed, performed the experiments. XLZ, LLX, XLY, JBT, FL, YLY, YJZ, YTT, CY analyzed the data and wrote the manuscript. CY and YTT edited the manuscript. All authors read and approved the final manuscript.

\section{Funding}

This work was supported by National Natural Science Foundation of China (No. 81700127, No. 81602735, No. 81701962, No. 81801967), Project of Hunan health and (No.C2016066), Natural science foundation of Hunan Province (No.2018JJ32589).

\section{Availability of data and materials}

All data generated or analyzed during this study are included in this published article.

\section{Ethics approval}

All animal protocols were approved by the Institutional Animal Care and Use Committees of Central South University.

\section{Consent for publication}

All authors have contributed to, read and approved the final version of this manuscript for submission and publication in the journal Molecular Medicine.

\section{Competing interests}

The authors declare that they have no competing interests.

\section{Author details}

${ }^{1}$ Department of Hematology and Critical Care Medicine, The 3rd Xiangya Hospital, Central South University, Changsha, Hunan Province 410000, P. R. China. ${ }^{2}$ Department of Pathophysiology, School of Basic Medical Science, Central South University, 138 Tong-zi-po Road, Changsha, Hunan Province 410000, P. R. China. ${ }^{3}$ Department of Physiology, School of Basic Medical Science, Central South University, Changsha, Hunan Province 410000, P. R. China. ${ }^{4}$ Department of Anesthesiology, Third Xiangya Hospital of Central South University, Changsha, Hunan, China. ${ }^{5} \mathrm{CU}$ Center, The Second Xiangya Hospital, Central South University, No. 139 Renmin Middle Road, Furong, Changsha 410011, Hunan, China.

Received: 21 October 2019 Accepted: 18 May 2020 Published online: 09 June 2020

\section{References}

Abe K. Therapeutic potential of neurotrophic factors and neural stem cells against ischemic brain injury. J Cereb Blood Flow Metab. 2000;20(10): 1393-408.

Amor S, Peferoen LA, Vogel DY, Breur M, van der Valk P, Baker D, van Noort JM. Inflammation in neurodegenerative diseases--an update. Immunology. 2014; 129(2):154-69. 
Annane D, Sharshar T. Cognitive decline after sepsis. Lancet Respir Med. 2015; 3(1):61-9.

Bevins RA, Besheer J. Object recognition in rats and mice: a one-trial nonmatching-to-sample learning task to study 'recognition memory'. Nature protocols. 2006;1(3):1306-11.

Block ML, Zecca L, Hong J-S. Microglia-mediated neurotoxicity: uncovering the molecular mechanisms. Nat Rev Neurosci. 2007;8(1):57-69.

Briz V, Restivo L, Pasciuto E, Juczewski K, Mercaldo V, Lo AC, Baatsen P, Gounko NV, Borreca A, Girardi T, Luca R, Nys J, Poorthuis RB, Mansvelder HD, Fisone G, Ammassari-Teule M, Arckens L, Krieger P, Meredith R, Bagni C. The noncoding RNA BC1 regulates experience-dependent structural plasticity and learning. Nat Commun. 2017:8(1):293.

Bunton CA. Oxidation of a-Diketones and a-Keto-Acids by hydrogen peroxide. Nature. 1949;163(4142):444.

Buras JA, Holzmann B, Sitkovsky M. Animal models of sepsis: setting the stage. Nat Rev Drug Discov. 2005;4(10):854-65.

Burguillos MA, Deierborg T, Kavanagh E, Persson A, Hajji N, Garcia-Quintanilla A, Cano J, Brundin P, Englund E, Venero JL. Caspase signalling controls microglia activation and neurotoxicity. Nature. 2011;472(7343):319.

Chen Q, Yu W, Shi J, Shen J, Gao T, Zhang J, Xi F, Li J, Li N. Insulin alleviates the inflammatory response and oxidative stress injury in cerebral tissues in septic rats. J Inflamm. 2014;11(1):18.

Cicalese L, Lee K, Schraut W, Watkins S, Borle A, Stanko R. Pyruvate prevents ischemia-reperfusion mucosal injury of rat small intestine. Am J Surg. 1996; 171(1):97-100.

Crestanello JA, Lingle DM, Millili J, Whitman GJ. Pyruvate improves myocardial tolerance to reperfusion injury by acting as an antioxidant: a chemiluminescence study. Surgery. 1998;124(1):92-9.

Da-ming S, Qun X, Wen-jing Y, Sahil G, Xi-ya Y, Jin-bao L, Jun W, Jia-feng $W$, Xiao-ming D. Resveratrol protects against sepsis-associated encephalopathy and inhibits the NLRP3/IL-1 $\beta$ axis in microglia. Mediators Inflamm. 2016;2016(3):1-10.

De ND, De Nardo CM, Latz E. New insights into mechanisms controlling the NLRP3 inflammasome and its role in lung disease. Am J Pathol. 2014;184(1): 42-54.

Deboer LW, Bekx PA, Han L, Steinke L. Pyruvate enhances recovery of rat hearts after ischemia and reperfusion by preventing free radical generation. Am J Physiol. 1993;265(5 Pt 2):H1571.

Delgado M, Ganea D. Vasoactive intestinal peptide prevents activated microgliainduced neurodegeneration under inflammatory conditions: potential therapeutic role in brain trauma. FASEB J. 2003;17(11):1922-4.

Delgado R, Carlin A, Airaghi L, Demitri MT, Meda L, Galimberti D, Baron P, Lipton JM, Catania A. Melanocortin peptides inhibit production of proinflammatory cytokines and nitric oxide by activated microglia. J Leukoc Biol. 1998;63(6): 740-5.

Dobsak P, Courderotmasuyer C, Zeller M, Vergely C, Laubriet A, Assem M, Eicher JC, Teyssier JR, Wolf JE, Rochette L. Antioxidative properties of pyruvate and protection of the ischemic rat heart during cardioplegia. J Cardiovasc Pharmacol. 1999;34(5):651-9.

Ebersoldt M, Sharshar T, Annane D. Sepsis-associated delirium. Intensive Care Med. 2007;33(6):941-50.

Eidelman LA, Putterman D, Putterman C, Sprung CL. The spectrum of septic encephalopathy. Definitions, etiologies, and mortalities. JAMA. 1996;275(6): 470.

Encinas J, Michurina T, Peunova N, Park JH, Tordo J, Peterson D, Fishell G, Koulakov A, Enikolopov G. Division-coupled astrocytic differentiation and age-related depletion of neural stem cells in the adult hippocampus. Cell Stem Cell. 2011;8(5):464-5.

Erickson MA, Banks WA. Cytokine and chemokine responses in serum and brain after single and repeated injections of lipopolysaccharide: multiplex quantification with path analysis. Brain Behav Immun. 2011;25(8):1637-48.

Fernandes-Alnemri T, Wu J, Yu JW, Datta P, Miller B, Jankowski W, Rosenberg S, Zhang J, Alnemri ES. The pyroptosome: a supramolecular assembly of ASC dimers mediating inflammatory cell death via caspase-1 activation. Cell Death Differ. 2007;14(9):1590.

Fink MP. Ethyl pyruvate: a novel anti-inflammatory agent. Crit Care Med. 2003; 261(4):349-62.

Fink MP. Ethyl pyruvate: a novel anti-inflammatory agent. J Intern Med. 2007; 261(4):349-62.

Franchi L, Warner N, Viani K, Nuñez G. Function of Nod-like receptors in microbial recognition and host defense. Immunol Rev. 2010;227(1):106-28.
Fu Q, Wu J, Zhou X-Y, Ji M-H, Mao Q-H, Li Q, Zong M-M, Zhou Z-Q, Yang J-J. NLRP3/Caspase-1 pathway-induced pyroptosis mediated cognitive deficits in a mouse model of sepsis-associated encephalopathy. Inflammation. 2018; 42(1):306-18.

Gaieski DF, Matthew EJ, Kallan MJ, Carr BG. Benchmarking the incidence and mortality of severe sepsis in the United States. Crit Care Med. 2013;41(5): 1167-74.

Genovese T, Esposito E, Mazzon E, Di PR, Meli R, Caminiti R, Bramanti P, Fink MP, Cuzzocrea S. Beneficial effects of ethyl pyruvate in a mouse model of spinal cord injury. Shock. 2009;32(2):217-27.

Gofton TE, Young GB. Sepsis-associated encephalopathy. Nat Rev Neurol. 2012; 8(10):557-66.

Green HF, Treacy E, Keohane AK, Sullivan AM, O'Keeffe GW, Nolan YM. A role for interleukin-1 beta in determining the lineage fate of embryonic rat hippocampal neural precursor cells. Mol Cell Neurosci. 2012;49(3):311-21.

Guo H, Callaway JB, Ting JP-Y. Inflammasomes: mechanism of action, role in disease, and therapeutics. Nat Med. 2015;21(7):677-87.

Han Y, Englert JA, Yang R, Delude RL, Fink MP. Ethyl pyruvate inhibits nuclear factor-kappaB-dependent signaling by directly targeting p65. J Pharmacol Exp Ther. 2005;312(3):1097-105.

Hauser B, Kick J, Asfar P, Ehrmann U, Albicini M, Vogt J, Wachter U, Brückner UB, Fink MP, Radermacher $P$. Ethyl pyruvate improves systemic and hepatosplanchnic hemodynamics and prevents lipid peroxidation in a porcine model of resuscitated hyperdynamic endotoxemia. Crit Care Med. 2005;33(9):2034-42.

He HJ, Wang Y, Le Y, Duan KM, Yan XB, Liao Q, Liao Y, Tong JB, Terrando N, Ouyang W. Surgery upregulates high mobility group box-1 and disrupts the blood-brain barrier causing cognitive dysfunction in aged rats. CNS Neurosci Ther. 2012;18(12):994-1002.

Heneka MT, Kummer MP, Latz E. Innate immune activation in neurodegenerative disease. Nat Rev Immunol. 2014;14(7):463-77.

Hise AG, Tomalka J, Ganesan S, Patel K, Hall BA, Brown GD, Fitzgerald KA. An essential role for the NLRP3 inflammasome in host defense against the human fungal pathogen Candida albicans. Cell Host Microbe. 2009;5(5):487-97.

Hoss F, Rodriguezalcazar JF, Latz E. Assembly and regulation of ASC specks. Cell Mol Life Sci. 2016;74(7):1211.

Huang LF, Yao YM, Zhang LT, Dong N, Yu Y, Sheng ZY. The effect of highmobility group box 1 protein on activity of regulatory $T$ cells after thermal injury in rats. Shock. 2008;31(3):322-9.

Hylden JLK, Wilcox GL. Intrathecal serotonin in mice: analgesia and inhibition of a spinal action of substance P. Life Sci. 1983;33(8):789-95.

Iwashyna TJ, Wesley EE, Smith DM, Langa KM. Long-term cognitive impairment and functional disability among survivors of severe sepsis. JAMA. 2010; 304(16):1787.

Jha S, Srivastava SY, Brickey WJ, locca H, Ting PY. The inflammasome sensor, NLRP3, regulates CNS inflammation and demyelination via caspase-1 and interleukin-18. J Neurosci. 2010;30(47):15811.

Kaufmann SHE, Dorhoi A, Hotchkiss RS, Bartenschlager R. Host-directed therapies for bacterial and viral infections. Nat Rev Drug Discov. 2018;17(1):35-56.

Kaukonen KM, Bailey M, Suzuki S, Pilcher D, Bellomo R. Mortality related to severe sepsis and septic shock among critically ill patients in Australia and New Zealand, 2000-2012. JAMA. 2014;311(13):1308-16.

Kim JJ, Diamond DM. The stressed hippocampus, synaptic plasticity and lost memories. Nat Rev Neurosci. 2002;3(6):453-62.

Kohman RA, Rhodes JS. Neurogenesis, inflammation and behavior. Brain Behav Immun. 2013;27(none):22-32.

Korff RWV. Pyruvate-C 14, purity and stability 放. Anal Biochem. 1964;8(2):171-8.

Kreisel T, Frank MG, Licht T, Reshef R, Ben-Menachem-Zidon O, Baratta MV, Maier SF, Yirmiya R. Dynamic microglial alterations underlie stress-induced depressive-like behavior and suppressed neurogenesis. Mol Psychiatry. 2014; 19(6):699-709.

Leger M, Quiedeville A, Bouet V, Haelewyn BT, Boulouard M, Schumann-Bard P, Freret T. Object recognition test in mice. Nature Protocols. 2013:8(12):2531-7.

Li S, Fang L, Kwan K, Tang Y, Wang X, Tang Y, Li J, Yang H, Chavan SS, Wang H. Identification of ethyl pyruvate as a NLRP3 inflammasome inhibitor that preserves mitochondrial integrity. Mol Med. 2018;24(1):8.

Mariathasan S, Newton K, Monack DM, Vucic D, French DM, Lee WP, Roosegirma M, Erickson S, Dixit VM. Differential activation of the inflammasome by caspase-1 adaptors ASC and Ipaf. Nature. 2004;430(6996):213-8.

Martin GS, Mannino DM, Eaton S, Moss M. The epidemiology of sepsis in the United States from 1979 through 2000. N Engl J Med. 2003;348(16):1546-54. 
Masters SL, Simon A, Aksentijevich I, Kastner DL. Horror autoinflammaticus: the molecular pathophysiology of autoinflammatory disease * . Annu Rev Immunol. 2009;27(27):621-68.

Matthews NC, Pfeffer PE, Mann EH, Kelly FJ, Corrigan CJ, Hawrylowicz CM, Lee TH. Urban particulate matter-activated human dendritic cells induce the expansion of potent inflammatory Th1, Th2 and Th17 effector cells. Am J Respir Cell Mol Biol. 2016;54(2):250

Miller AH, Maletic V, Raison CL. Inflammation and its discontents: the role of cytokines in the pathophysiology of major depression. Biol Psychiatry. 2009; 65(9):732-41.

Miyaji T, Hu X, Yuen PS, Muramatsu Y, Iyer S, Hewitt SM, Star RA. Ethyl pyruvate decreases sepsis-induced acute renal failure and multiple organ damage in aged mice. Kidney Int. 2003;64(5):1620-31.

Monje ML, Mizumatsu S, Fike JR, Palmer TD. Irradiation induces neural precursorcell dysfunction. Nat Med. 2002;8(9):955-62

Montgomery CM, Webb JL. Metabolic studies on heart mitochondria. II. The inhibitory action of parapyruvate on the tricarboxylic acid cycle. J Biol Chem. 1956;221(1):359-68.

Nath KA, Ngo EO, Hebbel RP, Croatt AJ, Zhou B, Nutter LM. alpha-Ketoacids scavenge $\mathrm{H}_{2} \mathrm{O} 2$ in vitro and in vivo and reduce menadione-induced DNA injury and cytotoxicity. Am J Physiol. 1995;268(1 Pt 1):C227.

Nixon K, Crews FT. Binge ethanol exposure decreases neurogenesis in adult rat hippocampus. J Neurochem. 2010:83(5):1087-93.

O'Neill J. Tackling drug-resistance infections globally: final report and recommendations. Review on antimicrobial resistance; 2016.

O'Donnell-Tormey J, Nathan CF, Lanks K, DeBoer CJ, De La Harpe J. Secretion of pyruvate. An antioxidant defense of mammalian cells. J Exp Med. 1987; 165(2):500-14

Organization, F. A, W. H. Organization. Summary of evaluations performed by the Joint FAOWHO Expert Committee on Food Additives (JECFA). Nutr Rev. 2010; 58(3):90

Polazzi E, Contestabile A. Reciprocal interactions between microglia and neurons: from survival to neuropathology. Rev Neurosci. 2002;13(3):221-42.

Qin L, Liu Y, Wang T, Wei SJ, Block ML, Wilson B, Liu B, Hong JS. NADPH oxidase mediates lipopolysaccharide-induced neurotoxicity and proinflammatory gene expression in activated microglia *. J Biol Chem. 2004;279(2):1415.

Qing W, Li F, Wang X, Quan C, Ouyang W, Liao Q. Inhibiting RIP1 improves chronic stress-induced cognitive impairments in D-galactose-induced aging mice. Front Behav Neurosci. 2018;12(undefined):234.

Salahudeen A, Clark EC, Nath K. Hydrogen peroxide-induced renal injury. A protective role for pyruvate in vitro and in vivo. J Clin Invest. 1991;88(6): 1886-93.

Sappington PL, Han X, Yang R, Delude RL, Fink MP. Ethyl pyruvate ameliorates intestinal epithelial barrier dysfunction in endotoxemic mice and immunostimulated caco-2 enterocytic monolayers. J Pharmacol Exp Ther. 2003;304(1):464-76

Sims CA, Wattanasirichaigoon S, Menconi MJ, Ajami AM, Fink MP. Ringer's ethyl pyruvate solution ameliorates ischemia/reperfusion-induced intestinal mucosal injury in rats. Crit Care Med. 2001;29(8):1513-8.

Singer M, Deutschman CS, Seymour CW, Shankar-Hari M, Annane D, Bauer M, Bellomo R, Bernard GR, Chiche JD, Coopersmith CM, Hotchkiss RS, Levy MM, Marshall JC, Martin GS, Opal SM, Rubenfeld GD, van der Poll T, Vincent JL, Angus DC. The third international consensus definitions for sepsis and septic shock (Sepsis-3). JAMA. 2016;315(8):801-10.

Slovin PN, Huang CJ, Cade JR, Wood CE, Skimming JW. Sodium pyruvate is better than sodium chloride as a resuscitation solution in a rodent model of profound hemorrhagic shock. Resuscitation. 2001;50(1):109-15.

Stevenson EK, Rubenstein AR, Radin GT, Wiener RS, Walkey AJ. Two decades of mortality trends among patients with severe sepsis: a comparative metaanalysis*. Crit Care Med. 2014;42(3):625-31.

Sui DM, Xie Q, Yi WJ, Gupta S, Yu XY, Li JB, Wang J, Wang JF, Deng XM. Resveratrol protects against sepsis-associated encephalopathy and inhibits the NLRP3/IL-1 $\beta$ axis in microglia. Mediators Inflamm. 2016;2016: 1045657

Tanriover, M. D., G. S. Guven, D. Sen, ., S. Unal, and O. Uzun. (2006). Epidemiology and outcome of sepsis in a tertiary-care hospital in a developing country. Epidemiol Infect 134(2): 315-322.

Tawadrous ZS, Delude RL, Fink MP. Resuscitation from hemorrhagic shock with Ringer's ethyl pyruvate solution improves survival and ameliorates intestinal mucosal hyperpermeability in rats. Shock. 2002;17(6):473.
Ulloa L, Ochani M, Yang H, Tanovic M, Halperin D, Yang R, Czura CJ, Fink MP, Tracey KJ. Ethyl pyruvate prevents lethality in mice with established lethal sepsis and systemic inflammation. Proc Natl Acad Sci U S A. 2002;99(19): 12351-6.

Venkataraman R, Kellum JA, Song M, Fink MP. Resuscitation with Ringer's ethyl pyruvate solution prolongs survival and modulates plasma cytokine and nitrite/nitrate concentrations in a rat model of lipopolysaccharide-induced shock. Shock. 2002;18(6):507-12.

Volmar CH, Salah-Uddin H, Janczura KJ, Halley P, Lambert G, Wodrich A, Manoah S, Patel NH, Sartor GC, Mehta N, Miles NT, Desse S, Dorcius D, Cameron MD, Brothers SP, Wahlestedt C. M344 promotes nonamyloidogenic amyloid precursor protein processing while normalizing Alzheimer's disease genes and improving memory. Proc Nat Acad Sci U S A. 2017;114(43):E9135-44.

Walsh JG, Muruve DA, Power C. Inflammasomes in the CNS. Nat Rev Neurosci. 2014;15(2):84-97.

Wang $\mathrm{H}$, Bloom $\mathrm{O}$, Zhang $\mathrm{M}$, Vishnubhakat JM, Ombrellino M, Che J, Frazier A, Yang $\mathrm{H}$, Ivanova S, Borovikova L, Manogue KR. HMG-1 as a late mediator of endotoxin lethality in mice. Science. 1999;285(5425):248-51.

Wang H, Liao H, Ochani M, Justiniani M, Lin X, Yang L, Al-Abed Y, Wang H, Metz C, Miller EJ, Tracey KJ, Ulloa L. Cholinergic agonists inhibit HMGB1 release and improve survival in experimental sepsis. Nat Med. 2004;10(11):1216-21.

Wang Q, Ding Q, Zhou Y, Gou X, Hou L, Chen S, Zhu Z, Xiong L. Ethyl pyruvate attenuates spinal cord ischemic injury with a wide therapeutic window through inhibiting high-mobility group box 1 release in rabbits. Anesthesiology. 2009;110(6):1279-86.

Weinberg SE, Sena LA, Chandel NS. Mitochondria in the regulation of innate and adaptive immunity. Immunity. 2015;42(3):406-17.

Wen $H$, Ting JP, O'Neill LAJ. A role for the NLRP3 inflammasome in metabolic diseases and did Warburg miss inflammation? Nat Immunol. 2012:13(4):352.

Widmann CN, Schewe JC, Heneka MT. Sepsis-associated encephalopathy versus sepsis-induced encephalopathy-authors' reply. Lancet Neurol. 2014;13(10):968-9.

Woo YJ, Taylor MD, Cohen JE, Jayasankar V, Bish LT, Burdick J, Pirolli TJ, Berry MF, Hsu V, Grand T. Ethyl pyruvate preserves cardiac function and attenuates oxidative injury after prolonged myocardial ischemia. J Thorac Cardiovasc Surg. 2004;127(5):1262-9.

Wu J, Dong L, Zhang M, Jia M, Zhang G, Qiu L, Ji M, Yang J. Class I histone deacetylase inhibitor valproic acid reverses cognitive deficits in a mouse model of septic encephalopathy. Neurochem Res. 2013;38(11):2440-9.

Wu MD, Hein AM, Moravan MJ, Shaftel SS, Olschowka JA, O'Banion MK. Adult murine hippocampal neurogenesis is inhibited by sustained IL-1 $\beta$ and not rescued by voluntary running. Brain Behav Immun. 2012;26(2):292-300.

Yan Y, Jiang W, Liu L, Wang X, Ding C, Tian Z, Zhou R. Dopamine controls systemic inflammation through inhibition of NLRP3 inflammasome. Cell. 2015;160(1-2):62-73.

Yang R, Han X, Delude RL, Fink MP. Ethyl pyruvate ameliorates acute alcoholinduced liver injury and inflammation in mice. J Lab Clin Med. 2003;142(5): 322-31.

Yende S, D'Angelo G, Kellum JA, Weissfeld L, Fine J, Welch RD, Kong L, Carter M, Angus DC. Inflammatory markers at hospital discharge predict subsequent mortality after pneumonia and sepsis. Am J Respir Crit Care Med. 2008; 177(11):1242-7.

Yeung ATY, Hale C, Xia J, Tate PH, Goulding D, Keane JA, Mukhopadhyay S, Forrester L, Billker O, Skarnes WC. Conditional-ready mouse embryonic stem cell derived macrophages enable the study of essential genes in macrophage function. Sci Rep. 2015;5:8908.

Zhang F, Jiang L. Neuroinflammation in Alzheimer's disease. Neuropsychiatr Dis Treat. 2015;14(4):243-56.

Zhang X, Xin X, Dong Y, Zhang Y, Yu B, Mao J, Xie Z. Surgical incision-induced nociception causes cognitive impairment and reduction in synaptic NMDA receptor 2B in mice. J Neurosci. 2013;33(45):17737-48.

Zhang Y, Liu L, Peng YL, Liu YZ, Wu TY, Shen XL, Zhou JR, Sun DY, Huang AJ, Wang $X$, Wang $Y X$, Jiang $C L$. Involvement of inflammasome activation in lipopolysaccharide-induced mice depressive-like behaviors. CNS Neurosci Ther. 2014;20(2):119-24.

\section{Publisher's Note}

Springer Nature remains neutral with regard to jurisdictional claims in published maps and institutional affiliations. 